\title{
Tribology Property of Laser Cladding Crack Free Ni/WC Composite Coating
}

\author{
Hu Cheng, Jian Yi, Zhigang Fang, Sheng Dai and Xianrui Zhao \\ College of Mechanical Engineering, Taizhou University, Taizhou 318000, P. R. China
}

\begin{abstract}
In order to improve wear resistance, the $\mathrm{Ni} / \mathrm{WC}$ composite coating was prepared on NAK80 mold steel surface by laser cladding technology. Phase and microstructure had been investigated by scanning electron microscopy (SEM), energy-dispersive spectroscopy (EDS) and X-ray diffraction (XRD). Dry sliding tribological properties at room temperature of the coating had been researched by ball-on-disc wear tests. Results indicated that phase constituents of the coating were mainly composed of $\mathrm{WC}_{2} \mathrm{~W}_{2} \mathrm{C}_{,} \mathrm{Cr}_{23} \mathrm{C}_{6}, \mathrm{NiCr}, \mathrm{CrB} 2$ and $\gamma-\mathrm{Ni}$, etc. There was a chemical metallurgical bonding between the coating and the steel substrate. Higher wear resistance of NAK80 mold steel was achieved after cladded by the $\mathrm{Ni} / \mathrm{WC}$ composite coating, which was mainly related to dendrite phases $\mathrm{Cr}_{23} \mathrm{C}_{6}$ and hard phases $\mathrm{WC}$, $\mathrm{W}_{2} \mathrm{C}$ dispersing in the coating. [doi:10.2320/matertrans.M2012237]
\end{abstract}

(Received July 4, 2012; Accepted October 25, 2012; Published November 30, 2012)

Keywords: laser cladding, coatings, microstructure, tribological property, wear

\section{Introduction}

NAK80 mold steel was used for precise and complex plastic mold cavity material due to its good mechanical property, high harden-ability and good mirror polishing ability. However, the poor wear resistance would seriously shorten the life of NAK 80 steel. So the wear resistance of NAK80 steel should be improved, especially used for precise mold cavity. Miao et al. found that the surface quality and fatigue life of NAK80 steel could be improved by the shot peening. ${ }^{1)}$ However, the shot peening would cause deformation or cracking of the work pieces easily, which can't meet the surface quality requirements of precise mold. Therefore, some other advanced surface treatment technologies should be used in order to reduce the deformation of mold during surface treatment. Laser cladding was a hardfacing process that used high power density to melt the feeding material and formed a thin coating with thin heat-affected zone, minimum deformation and low dilution with the substrate, ${ }^{2,3)}$ which had a bright application prospects in the field of mold surface treatment. $^{4-7)}$

Due to relatively high hardness and high wear resistance of WC, and good wet-ability of Ni on WC surface, studies on laser clad $\mathrm{Ni} / \mathrm{WC}$ composite coatings were reported extensively, ${ }^{8-12)}$ these researches mainly focused on the tribological properties of the coatings. K. Van Acker et al. and $\mathrm{Wu}$ et al. analyzed the influence of $\mathrm{WC}$ particle (including size, distribution etc.) on the wear resistance of the laser clad Ni/WC composite coatings. ${ }^{9,10)}$ Chen et al. studied the microstructure and phase transformation of laser clad WC/Ni60B coatings during dry sliding wear. Results indicated that under higher load, the new fine precipitated phase $\mathrm{WC}$ or $\mathrm{WC}_{1-x}$ made the hardness increase of the coatings and the amount of the precipitated phase increased with the nanometer WC content increasing in the coatings. ${ }^{11)}$ However, there were still some urgent problems to be solved about how to improve the wear resistance of Ni/WC coating prepared by laser cladding, for example, WC phase dissolution into Ni-based alloy and too much cracks in coating both would decrease the wear resistance of $\mathrm{Ni} / \mathrm{WC}$ coating. So it was crucial to reduce the dissolution of WC phase, and provide dense (cracks free) coating for increasing wear resistance of $\mathrm{Ni} / \mathrm{WC}$ coating prepared by laser cladding.

In this paper, the dense and nearly crack free $\mathrm{Ni} / \mathrm{WC}$ coating was prepared on NAK80 steel substrate by laser cladding technology. Moreover, the effect of $\mathrm{Ni} / \mathrm{WC}$ coating on wear resistance of NAK80 steel was investigated.

\section{Experimental Aspects}

The chemical compositions (mass\%) of NAK80 mold steel were shown in Table 1. It was machined into rectangular bulk with the dimension of $50 \times 50 \times 20 \mathrm{~mm}$. The substrate surface was polished and degreased in acetone before coating.

The Ni/WC powders were uniformly mixed with $80 \% \mathrm{Ni}$ based alloy powder (its chemical compositions were shown in Table 2) and 20\% tungsten carbide powder, and selected as the precursor materials for fabricating the $\mathrm{Ni} / \mathrm{WC}$ composite coating by laser cladding process. The particle size of $\mathrm{Ni}$ based alloy powder ranged from 200 to 300 mesh, and that of tungsten carbide powder ranged from 100 to 150 mesh. They were mixed with a binder to form a slurry and then preplaced on the substrate and then dried in a furnace at $100^{\circ} \mathrm{C}$ for $10 \mathrm{~h}$. The mixed alloy powder thickness used in laser cladding experiment was about $1.0 \mathrm{~mm}$, and the NAK80 steel substrate was heated to about $350^{\circ} \mathrm{C}$ before laser cladding. The laser cladding experiment was carried out with an applied power of $2.0 \mathrm{~kW}$, a beam diameter of $3 \mathrm{~mm}$, a defocusing amount of $40 \mathrm{~mm}$ and lap of $30 \%$ at a low scanning speed of $6 \mathrm{~mm} / \mathrm{s}$ by $\mathrm{CO}_{2}$ laser.

Table 1 Chemical compositions of NAK80 mold steel (mass\%).

\begin{tabular}{cccccccc}
\hline $\mathrm{C}$ & $\mathrm{Si}$ & $\mathrm{Mn}$ & $\mathrm{Ni}$ & $\mathrm{Al}$ & $\mathrm{Cu}$ & $\mathrm{Mo}$ & $\mathrm{Fe}$ \\
\hline $0.05-0.18$ & $0.15-1.0$ & $1-2$ & $2.5-3.5$ & $0.5-1.5$ & $0.7-1.5$ & $0.1-0.4$ & Bal. \\
\hline
\end{tabular}

Table 2 Chemical compositions of Ni-based alloy powder (mass\%).

\begin{tabular}{ccccccc}
\hline C & Cr & B & Si & Mo & Fe & Ni \\
\hline 0.5 & 15 & 4 & 3 & 3.5 & 3.3 & Bal. \\
\hline
\end{tabular}


After laser cladding, metallographic samples were prepared using mechanical polishing procedures, and chemically etched in $\mathrm{HF}: \mathrm{HNO}_{3}: \mathrm{H}_{2} \mathrm{O}$ (volume ratio $1: 6: 7$ ) solution for approximately $30-40 \mathrm{~s}$. Microstructure characterization of the coating was carried out by Hitachi S-4800 scanning electron microscope (SEM), and energy dispersive spectroscopy (EDS). Phase analysis of the coating and raw powder was conducted by using a Philips PW type X-ray diffraction (XRD) $\left(\mathrm{CuK}_{\alpha}\right.$ radiation). Hardness of the coating surface and cross-section were measured by using a HXD$1000 \mathrm{~T}$ Vickers microhardness tester with a test load of $5 \mathrm{~N}$ and a load-dwell time of $15 \mathrm{~s}$.

Wear tests were conducted on a ball-on-disc metallic dry sliding wear tester (made in Lanzhou Institute of Chemical Physics, Chinese Academy of Sciences). The samples of the coating and NAK80 mold steel for wear tests were machined to $10 \times 10 \times 5 \mathrm{~mm}$ in size by electric discharging machining. The $10 \times 10 \mathrm{~mm}$ surface was used as the tested surface. The surface roughness of the samples were about Ra $0.4 \mu \mathrm{m}$ after polishing. The disc counterpart was an AISI 52100 bearing steel ball with an average hardness of HV 600 . The wear tests were carried out at room temperature with a load of $0.33 \mathrm{~kg}$, sliding velocity about $0.5 \mathrm{~m} \cdot \mathrm{s}^{-1}$ and operating time of $30 \mathrm{~min}$. The 3D topography, average width and depth of wear scars were measured by a 3D surface profilometer. To evaluate the wear resistance of the samples, the wear volume $V_{\mathrm{w}}$ and wear rate $K$ were given as follows: ${ }^{13)}$

$$
\begin{aligned}
V_{\mathrm{w}} & =2 \pi h r\left(3 h^{2}+4 b^{2}\right) / 6 b \\
K & =V_{\mathrm{w}} / P S
\end{aligned}
$$

where $h$ was the wear average depth $(\mu \mathrm{m}), b$ was the wear average width $(\mathrm{mm}), r$ was the wear orbital radius $(\mathrm{mm}), P$ was the normal load (N) and $S$ was the slide distance (m).

\section{Results and Discussion}

\subsection{The phases and microstructure analysis}

As indicated by XRD analysis results in Fig. 1, the phase constituents of the composite coating were mainly composed of $\mathrm{WC}, \mathrm{W}_{2} \mathrm{C}, \mathrm{Cr}_{23} \mathrm{C}_{6}, \mathrm{NiCr}, \mathrm{CrB}_{2}$ and $\gamma$-Ni etc. Figure 2 showed the surface morphology of the coating, it can be seen that the quality of the coating was good and there were nearly no cracks, pores and other inclusions in the coating. Many white and block phases and dendrite phases were dispersed in the coating. EDS analysis was carried out to determine the structure of white and block phases. The result taken from one of those white and block phases gave the composition of $\mathrm{C} 14$ and W86 in mass\%. According to XRD analysis result, it can be concluded that the white and block phase was tungsten carbide $\left(\mathrm{WC}+\mathrm{W}_{2} \mathrm{C}\right)$. During the fabrication process of the coating, the molten pool rapidly solidified with tungsten carbide and the substrate as the core, which resulted in the formation of dendrite phases. According to the EDS and XRD results, the dendrite phase was confirmed to be $\mathrm{Cr}_{23} \mathrm{C}_{6}$ with an approximate composition of $42 \mathrm{Cr}-50 \mathrm{C}-$ $2 \mathrm{Fe}-6 \mathrm{~W}$ (at $\%$ ), matrix phase of the coating was confirmed to be $\gamma-\mathrm{Ni}$ with a composition of $58 \mathrm{Ni}-21 \mathrm{C}-11 \mathrm{Fe}-6 \mathrm{Si}-4 \mathrm{Cr}$ (at\%).

The cross-section morphologies of the coating were shown in Fig. 3. The SEM image of the coating/substrate transition zone was shown as a smooth bright layer about $1 \mu \mathrm{m}$ in width and dendrites vertical to the interface between the coating and the substrate (Fig. 3(b)). The smooth bright layer had a composition of approximately $60 \mathrm{Fe}-27 \mathrm{C}-11 \mathrm{Ni}-2 \mathrm{Cr}$ (at $\%$ ), and it was identified as Ni-rich Fe-based solid solution phase. Figure 4 showed the results of EDS line analysis from the coating to the substrate at the interface location. It can be seen that the content of element Fe gradually increased from the coating to the substrate, while the content of element $\mathrm{Ni}$ and $\mathrm{Cr}$ markedly decreased at the interface. These showed that during the period of cladding $\mathrm{Ni} / \mathrm{WC}$ powders on NAK80 steel, Fe element in the steel substrate diffused to the coating near the interface and there was a chemical metallurgical bonding between the coating and the steel substrate.

The microstructure at the interface between the coating and the substrate was relevant with the temperature on the substrate surface during the coating formation. During laser

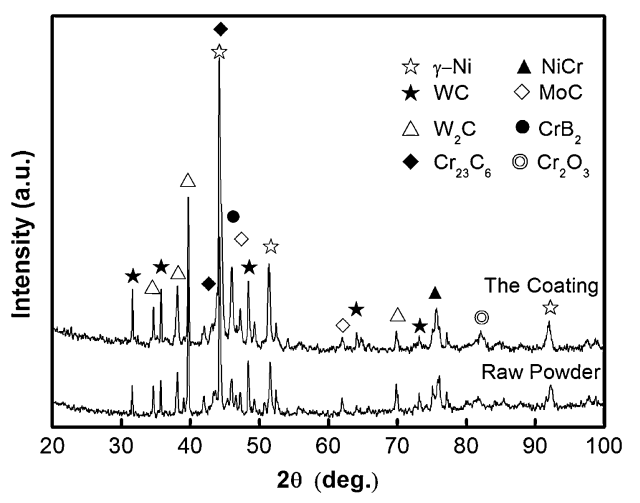

Fig. 1 XRD patterns of the laser cladding Ni/WC composite coating.
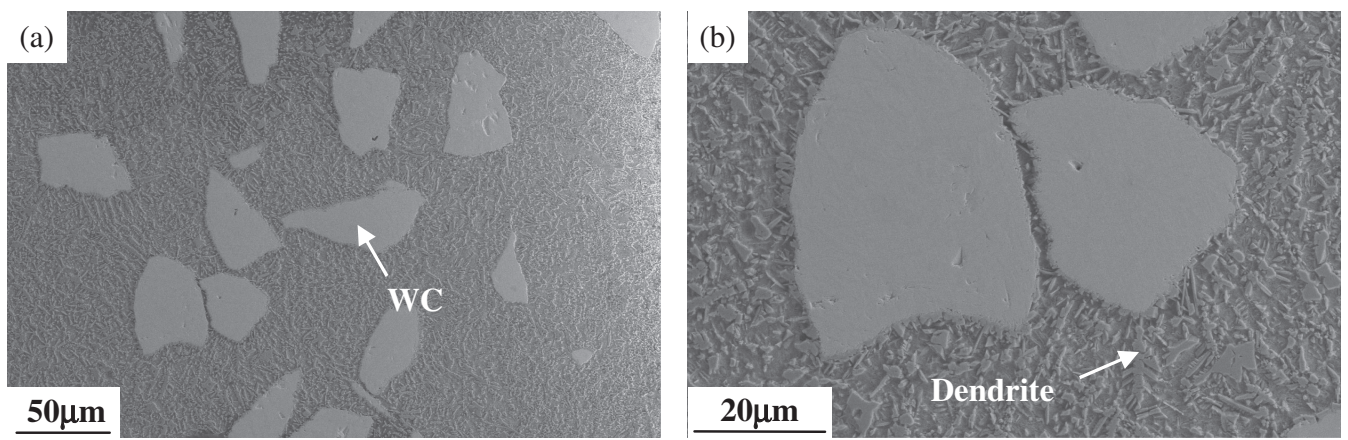

Fig. 2 Surface morphologies of the laser cladding coating. 

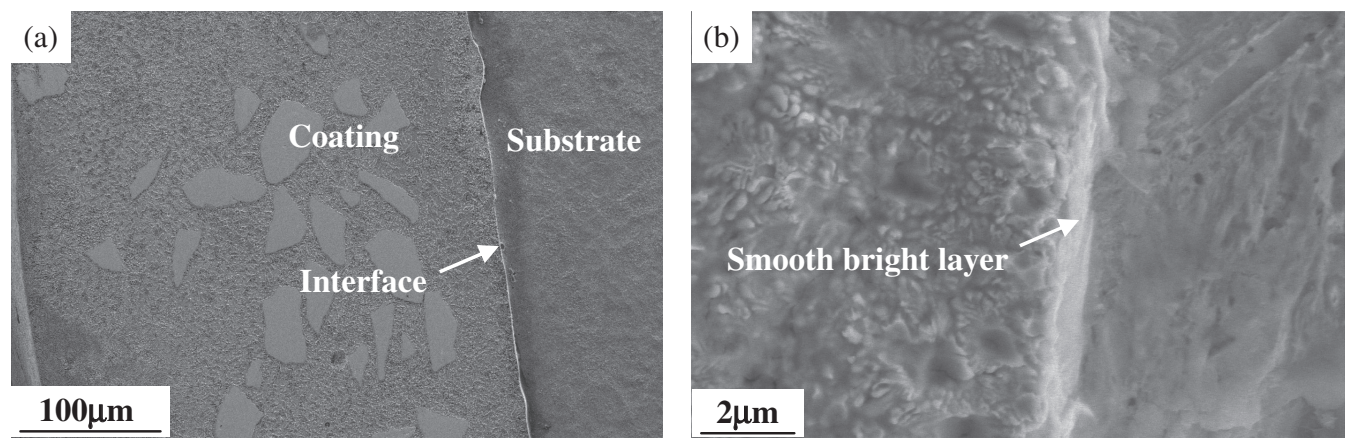

Fig. 3 Cross-section morphologies of the laser clad Ni/WC composite coating on substrate of NAK80 mold steel: (a) Low magnification SEM image; (b) High magnification SEM image.
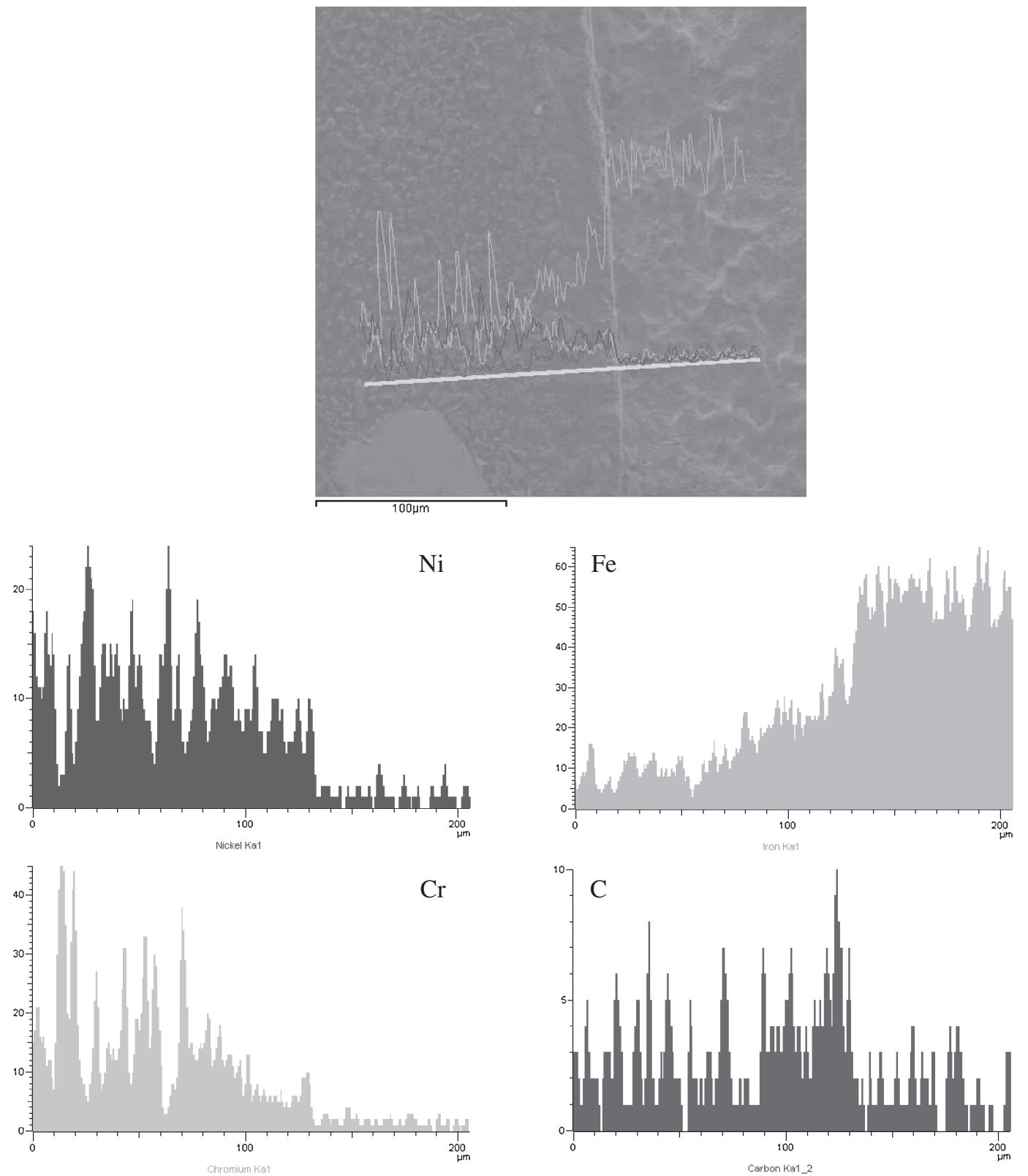

Fig. 4 EDS line analysis from the coating to the substrate at the interface location.

cladding $\mathrm{Ni} / \mathrm{WC}$ on NAK80 steel, the temperature on the substrate surface was very high (nearly reaching the melting point of the substrate). Fe element in the substrate diffused to the coating. When the molten powder solidifying, $\mathrm{Fe}-\mathrm{Ni}$ solid solution phases formed from $\gamma$-Fe and $\gamma$-Ni at the interface between the coating and the substrate, then the solid solution phases grew at the interface by the diffusion of element $\mathrm{Ni}$ from the molten $\mathrm{Ni} / \mathrm{WC}$ alloy, and the Ni-rich 
Fe-based solid solution phases formed at the interface. As solid-liquid interface moving to the coating, temperature gradient would be reduced and cooling speed would be increased. It resulted in emitting and enriching of the solutes on the front edge of solidified alloy and forming of the dendrites vertical to the interface.

\subsection{The microhardness and tribology property analysis}

The microhardness profile along the depth direction of the laser clad coating was shown in Fig. 5. It was apparent that there was an intergradation of hardness at the interface between the coating and substrate, which was beneficial for enhancing the adhesion of the coating to substrate. The hardness was in the range of HV 700-HV 900 in the coating zone, even exceeding HV 1200 in WC region, and in the range of HV $350-\mathrm{HV} 400$ in the substrate. The average hardness of the coating was about HV 800, it was approximately two times that (about HV 400) of NAK80 steel substrate. The hardness of the coating was higher than that of NAK80 steel substrate, because the molten pool rapidly solidified during laser cladding which resulted in fine grain strengthening. Moreover, the elements $\mathrm{Cr}$, Mo can form

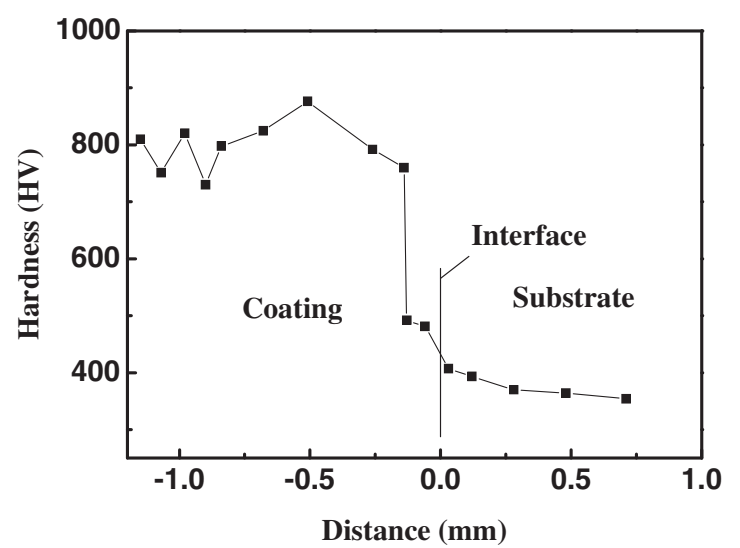

Fig. 5 Microhardness profile of the laser clad Ni/WC composite coating.

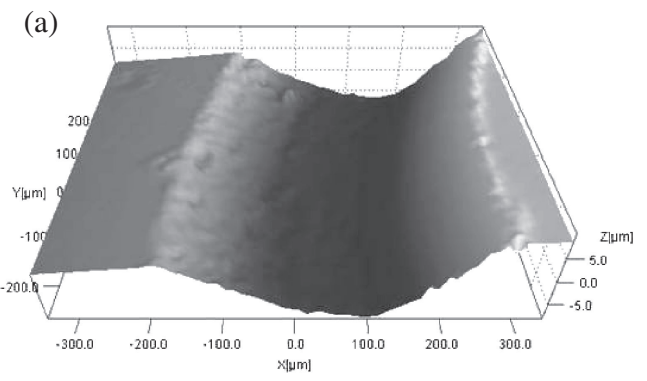

solid solution with $\gamma$-Ni which resulted in solid solution strengthening. At last, the hard phases $\mathrm{WC}, \mathrm{W}_{2} \mathrm{C}, \mathrm{Cr}_{23} \mathrm{C}_{6}$ dispersed in $\gamma$-Ni substrate which resulted in dispersion reinforcement.

In order to evaluate the wear resistance of the coating on NAK80 steel substrate, the tribology properties of the coating sample and NAK80 steel sample were tested by the ball-ondisc metallic dry sliding wear tester respectively. The results showed that the bonding between the coating and the substrate remained undamaged after the test and there was no flaking of the coating from the substrate under the test condition.

Wear scar 3D topographies of the coating and NAK80 steel substrate were shown in Fig. 6. As can be seen from Fig. 6, wear scar width and depth of NAK80 steel substrate were higher than those of the coating sample. Wear volume and wear rate of the wear scars were calculated by the formula (1) and (2), the results were shown in Table 3. It showed that the wear volume and wear rate of the coating sample were far less than those of NAK80 steel sample. It can be concluded that wear rate of NAK80 steel was reduced about 99.6 percent after laser cladding treatment and its wear behavior was improved noticeably by the coating.

Figure 7 showed the worn surface morphologies of the coating and NAK80 steel after a dry sliding wear test at the applied test load of $0.33 \mathrm{~kg}$. Under the sliding wear conditions, since the hardness of NAK80 steel (about HV 400) was lower than that of the AISI 52100 bearing steel ball (about HV 600), it was easy for the hard asperities on the surface of the AISI 52100 bearing steel ball to penetrate into the contact surface of NAK 80 steel, ${ }^{14)}$ which resulted in plowing grooves and plastic deformation on the worn surface of NAK80 steel (see Fig. 7(a)). The AISI 52100 bearing steel ball with higher hardness than that of NAK80 steel had the better abilities of plastic deformation and abrasive wear resistance than those of NAK80 steel. In addition, detaching debris were also found on the worn surface of NAK80 steel (see Fig. 7(a)). EDS analysis result

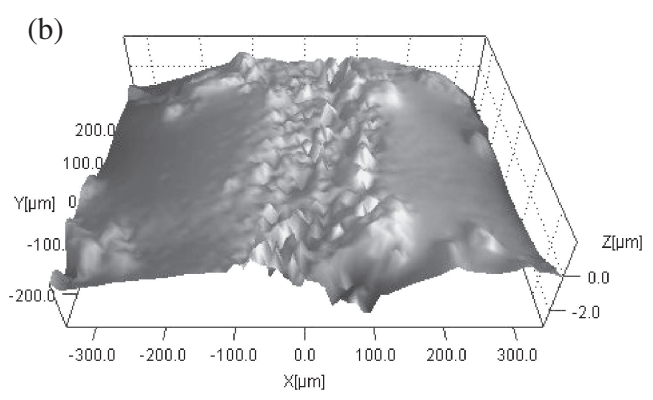

Fig. 6 3D topographies of wear scars for two friction samples: (a) NAK80 substrate; (b) Ni/WC composite coating.

Table 3 Wear volume and wear rate of friction samples.

\begin{tabular}{cccc}
\hline Sample & $\begin{array}{c}\text { Average width } \\
\text { of wear scar } \\
b / \mathrm{mm}\end{array}$ & $\begin{array}{c}\text { Average depth } \\
\text { of wear scar } \\
h / \mathrm{mm}\end{array}$ & $\begin{array}{c}\text { Wear volume } \\
V_{\mathrm{w}} / \mathrm{mm}^{3}\end{array}$ \\
\hline NAK80 steel substrate & 0.482 & $9.45 \times 10^{-3}$ & $8.863 \times 10^{-3}$ \\
The laser clad Ni/WC coating & 0.162 & $1.04 \times 10^{-3}$ & $0.037 \times 10^{-3}$ \\
\hline
\end{tabular}

Note: $r=2 \mathrm{~mm} ; P=3.234 \mathrm{~N} ; S=211.115 \mathrm{~m}$. 

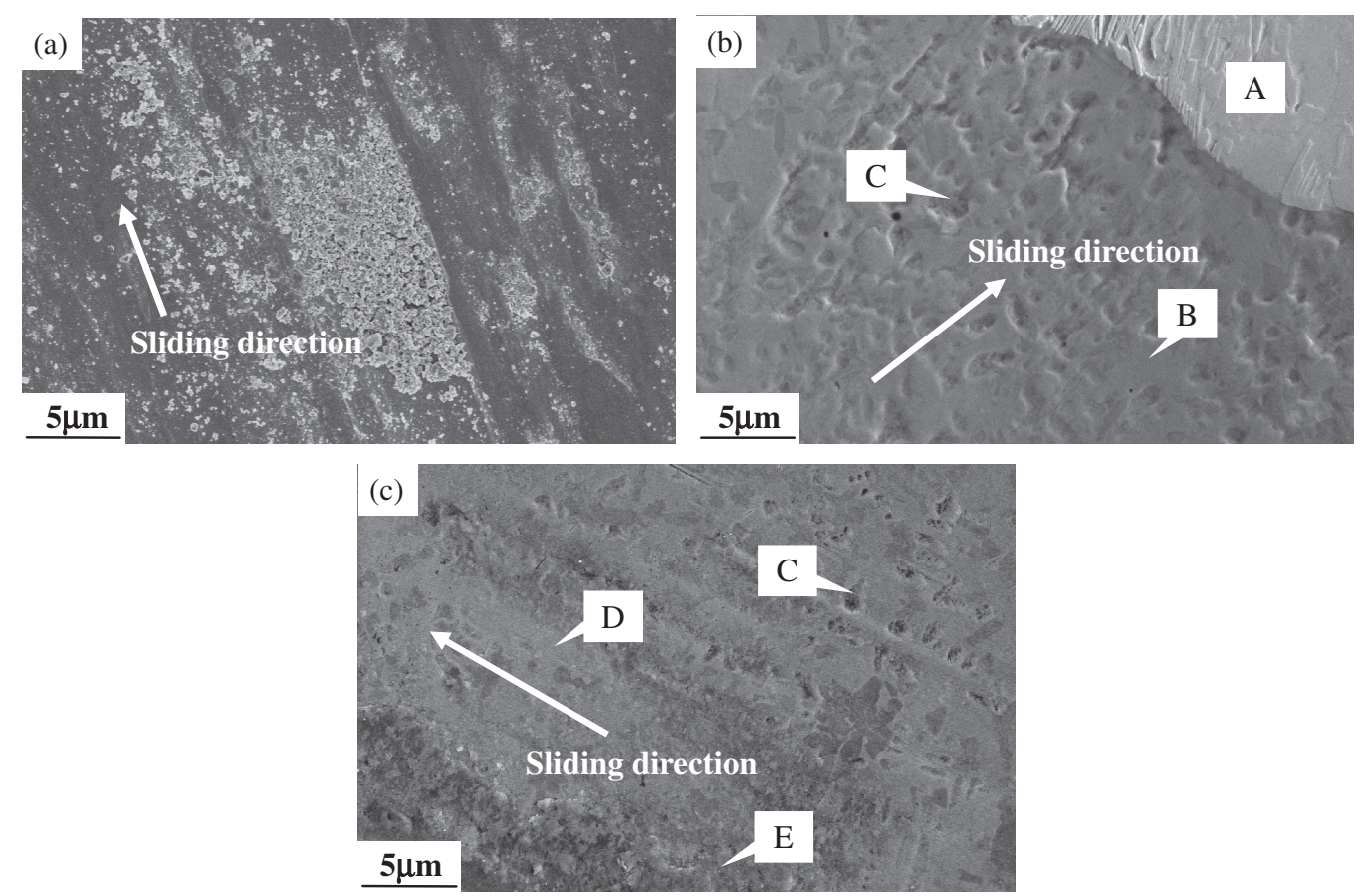

Fig. 7 SEM morphologies of worn surfaces: (a) NAK80 steel; (b) and (c) Ni/WC composite coating.

showed that the wear debris were mainly composed of $\mathrm{Fe}$ element, and a small amount of $\mathrm{C}, \mathrm{Mn}, \mathrm{Ni}, \mathrm{Cu}$ and $\mathrm{Al}$ elements $(94.15 \mathrm{Fe}-0.11 \mathrm{C}-1.32 \mathrm{Mn}-2.57 \mathrm{Ni}-0.98 \mathrm{Cu}-0.87 \mathrm{Al}$, mass\%), which were primarily detached from NAK80 steel. The above-mentioned evidences indicated that the main wear mechanism of NAK80 steel under the sliding wear conditions was abrasion wear and adhesion wear. The mixture of abrasion wear and adhesive wear accelerated the wear amount of NAK80 steel. $^{14-17)}$

As shown in Figs. 7(b) and 7(c), there only existed light scratches on the worn surface of the coating. Due to hard phase $\mathrm{WC}, \mathrm{W}_{2} \mathrm{C}$ and $\mathrm{Cr}_{23} \mathrm{C}_{6}$ being dispersed in the coating (Fig. 2), the surface hardness was improved significantly, so the ability of plastic deformation and adhesive wear resistance of the coating was enhanced noticeably compared to NAK80 steel. During the grinding with the AISI 52100 bearing steel ball, the bonding phase $\gamma-\mathrm{Ni}$ in the coating was worn away first due to hardness of $\gamma$-Ni far lower than that of hard phases $\mathrm{WC}, \mathrm{W}_{2} \mathrm{C}$ and $\mathrm{Cr}_{23} \mathrm{C}_{6}$. Once the hard phases WC, $\mathrm{W}_{2} \mathrm{C}$ and $\mathrm{Cr}_{23} \mathrm{C}_{6}$ were exposed to the worn surface, the loss of the coating would decline, which resulted in a favorable abrasive wear resistance. However, the mating steel ball suffered from greater abrasive wear by the coating, due to whose surface hardness lower than that of the coating. So the main wear mechanism of the coating was abrasive wear accompanied with light micro-cutting. It can also be concluded that wear resistance of NAK80 steel was improved significantly by the laser clad Ni/WC composite coating.

The compositions in different regions on the worn surface of the coating (Figs. 7(b) and 7(c)) were shown in Table 4. From the SEM morphologies and EDS analysis results, it was known that region A was mainly composed of $\mathrm{WC}$, whose wear resistance was the best. Region B and D were mainly composed of Ni-based alloy and element W, light scratches can be found on their surface, their wear resistance was only
Table 4 Composition distribution on worn surface of the Ni/WC composite coating on substrate of NAK80 steel (at\%).

\begin{tabular}{cccrccc}
\hline Composition & $\mathrm{C}$ & $\mathrm{Si}$ & $\mathrm{Cr}$ & $\mathrm{Fe}$ & $\mathrm{Ni}$ & \multicolumn{1}{c}{$\mathrm{W}$} \\
\hline $\mathrm{A}$ & 62.63 & - & - & - & - & 37.37 \\
$\mathrm{~B}$ & 33.82 & 1.54 & 33.98 & 6.86 & 18.29 & 5.51 \\
$\mathrm{C}$ & 45.88 & 3.05 & 3.65 & 11.07 & 35.92 & 0.44 \\
$\mathrm{D}$ & 15.85 & 3.06 & 27.59 & 16.18 & 34.06 & 3.27 \\
$\mathrm{E}$ & 17.23 & - & 49.05 & 21.92 & 11.80 & - \\
\hline
\end{tabular}

Note: A, B, C, D, E marked in Fig. 7.

a little poorer than that in region A. During laser cladding, partial WC was melted and decomposed, decomposed element $\mathrm{W}$ could dissolve into dendrite $\mathrm{Cr}_{23} \mathrm{C}_{6}$ and $\gamma$-Ni which resulted in solid solution strengthening. Because element $\mathrm{W}$ did not dissolve into Ni-based alloy in region $\mathrm{E}$, its surface wear mark was deeper than that in region A, B and $\mathrm{D}$, so its wear resistance was relatively weaker. Region $\mathrm{C}$ was the region of $\gamma$-Ni matrix phase, its wear resistance was the weakest. It was concluded that wear resistance in the region of Ni-based alloy with element $\mathrm{W}$ was higher than that in the region without element $\mathrm{W}$ in the $\mathrm{Ni} / \mathrm{WC}$ composite coating, partially melted WC dissolving into Ni-based alloy was beneficial for enhancing the bonding capacity between WC and Ni-based alloy. But excessive melting of WC would decrease the effect of $\mathrm{WC}$ on disperse reinforcement and grain refining strengthening of the coating, which resulted in decreasing wear resistance of the coating. So the suitable technology should be chosen correctly, and the melting degree of WC should be controlled during laser cladding $\mathrm{Ni} / \mathrm{WC}$ composite coating. The technology about laser cladding Ni/WC composite coating on NAK80 mold steel substrate needed further study. 


\section{Conclusions}

(1) $\mathrm{Ni} / \mathrm{WC}$ composite coating was successfully fabricated on NAK80 mold steel by laser cladding process. There was a chemical metallurgical bonding between coating and steel substrate under the experimental condition. The coating mainly consisted of $\mathrm{WC}, \mathrm{W}_{2} \mathrm{C}, \mathrm{Cr}_{23} \mathrm{C}_{6}, \mathrm{NiCr}, \mathrm{CrB}_{2}$ and $\gamma-\mathrm{Ni}$ etc. Dendrite phases $\mathrm{Cr}_{23} \mathrm{C}_{6}$ and hard phases $\mathrm{WC}, \mathrm{W}_{2} \mathrm{C}$ were dispersed in the coating, which enhanced the hardness of the coating surface significantly. The average hardness of the coating was approximately two times that of the original NAK80 mold steel. The coating improved the wear resistance of NAK80 steel surface significantly under room-temperature dry sliding wear test conditions.

(2) The main wear mechanism of the coating was abrasive wear accompanied with light micro-cutting, while the main wear mechanism of the original NAK80 mold steel was the mixture of abrasion wear and adhesive wear. Dense and nearly cracks free was beneficial to improve wear resistance of $\mathrm{Ni} / \mathrm{WC}$ composite coating.

\section{Acknowledgements}

The authors acknowledge support by the National Natural Science Foundation of China (Grant No. 51002101) and Postdoctoral Science Foundation of China (Grant No. 20110490349).

\section{REFERENCES}

1) H. Miao, D. W. Zuo, H. F. Wang and X. W. Sha: Key Eng. Mater. 426427 (2010) 537-539.

2) A. S. C. M. d'Oliveira, R. Vilar and C. G. Feder: Appl. Sur. Sci. 201 (2002) 154-160.

3) N. A. McPherson, K. Chi and T. N. Baker: J. Mater. Process. Tech. 134 (2003) 174-179.

4) C. Navas, A. Conde, B. J. Fernndez, F. Zubiri and J. Dedamborenea: Surf. Coat. Tech. 194 (2005) 136-142.

5) J. Y. Chen, K. Conlon, L. Xue and R. Rogge: Mater. Sci. Eng. A 527 (2010) 7265-7273.

6) W. Zhang: Phys. Procedia 25 (2012) 200-204.

7) J. Choi and Y. Chang: Int. J. Mach. Tools Manuf. 45 (2005) 597-607.

8) C. Guo, J. S. Zhou, J. M. Chen, J. R. Zhao, Y. J. Yu and H. D. Zhou: Wear 270 (2011) 492-498.

9) K. Van Acker, D. Vanhoyweghen, R. Persoons and J. Vangrunderbeek: Wear 258 (2005) 194-202.

10) P. Wu, H. M. Du, X. L. Chen, Z. Q. Li, H. L. Bai and E. Y. Jiang: Wear 257 (2004) 142-147.

11) H. H. Chen, C. Y. Xu, J. Chen, H. Y. Zhao, L. Zhang and Z. T. Wang: Wear 264 (2008) 487-493.

12) L. St-Georges: Wear 263 (2007) 562-566.

13) E. Broszeit, B. Matthes, W. Herr and K. H. Kloos: Surf. Coat. Technol. 58 (1993) 29-35.

14) B. G. Guo, J. S. Zhou, S. T. Zhang and H. D. Zhou: Appl. Sur. Sci. 253 (2007) 9301-9310.

15) M. Masanta, S. M. Shariff and A. R. Choudhury: Wear 271 (2011) 1124-1133.

16) Y. J. Dong and H. M. Wang: Surf. Coat. Tech. 204 (2009) 731-735.

17) X. B. Liu and H. M. Wang: Wear 262 (2007) 514-521. 